\title{
PROMOTING THE SYSTEM OF LEADING CADRES CONTACTING CLASSES AND INNOVATING THE BRAND OF UNIVERSITY STUDENTS' EDUCATION
}

\author{
Qinghui Zeng ${ }^{1}$, Yong Wang ${ }^{2^{*}}$, Lin Pan $^{3^{*}}$ \\ ${ }^{1}$ Dr, Jinan University, China, 93430749@qq.com \\ ${ }^{2} \mathrm{Dr}$, Jinan University, China,1057394877@qq.com \\ ${ }^{3}$ Dr, Jinan University, China, 149768127@qq.com \\ ${ }^{*}$ Corresponding Author
}

\begin{abstract}
Class is the basic organization form of university students and the main organization carrier of university students' self-education, self-management and self-service. The success or failure of class management is related to the growth of every university student, to the quality of talent training in colleges and universities, and to the long-term development of teaching and educating people in colleges and universities. The research data show that promoting the system of leading cadres' contact with class is conducive to creating a healthy, harmonious, united and cooperative class atmosphere, and promoting the all-round development of university students' morality, intelligence, physique, aesthetics and labor.
\end{abstract}

Keywords: Leading cadres, Class management, Higher education, Innovative brand.

\section{INTRODUCTION}

University class is the most basic unit of students in school, the most basic organization of teaching management activities, the important organization carrier of satisfying students' growth, promoting students' self-service, self-education, self-management and all-round development, and the important support of ideological education for university students. The success or failure of university class management directly affects the quality of education and the growth of every university student (Shao Nana, Zhang Hongxia., 2020, pp. 58-59,62;Bi Qingbo. (2015), pp.189-190).

In order to promote the implementation of the project of improving the quality of Ideological education in colleges and universities, vigorously strengthen and improve the education of university students, at the same time, combined with the working concept of management education and service education, explore a new platform for university students' education, implement the system of "leading cadres contacting classes", promote leading cadres contacting grass-roots classes and students, and promote university education throughout the whole process of student training, to achieve the whole process of all-round education.

\section{THE IMPLEMENTATION AND EFFECT OF THE SYSTEM OF LEADING CADRES CONTACTING CLASSES}

Jinan University has more than 1000 classes, leading cadres contact class related work in more than 200 classes. Leaders at all levels participate in class construction by participating in class meetings and other ways to deeply understand the situation of students, carry out targeted education and guidance work according to the characteristics of students in the class, solve various problems of students outside the classroom, and escort the learning and development of students. 
Since the trial implementation of the "leading cadres contact class" system, the school's leading cadres have responded positively. Up to now, five groups of leading cadres have volunteered to serve as class tutors to participate in the contact class work, with more than 1000 times of participation.

Through class meetings, symposiums, lectures, social investigation and other forms, leading cadres have strengthened their contact with the class and achieved good results. According to the statistics in recent years, nearly $30 \%$ of the classes contacted by leading cadres have won the honorary titles of advanced class group, 5A excellent class group, May 4th Red Flag League branch and May 4th Red Flag League branch of Guangdong Province, which is about $22 \%$ higher than the average prize winning rate of the whole school; nearly $45 \%$ of the classes contacted by leading cadres have won the awards of international, national, provincial and school levels Class scholarships, honorary titles and awards in various competitions, higher than the average award rate of the whole school students about $36 \%$. It can be seen that leading cadres play a good role in guiding and promoting class growth and students' learning and development. At the same time, through direct docking with the class, leading cadres can enhance the communication with management service objects, understand the grassroots and students better, and promote the effective development of management education and service education to a certain extent. According to the survey data, more than $50 \%$ of the leading cadres think that contacting the class can greatly promote their work, and more than $10 \%$ of the leading cadres think that it is of great help to their work.

Based on the feedback of teachers and students in recent years, there is still room for improvement in the system of leading cadres contacting classes, which needs more attention and further support from the school. It is of far-reaching significance and broad prospects to promote the system of leading cadres connecting with classes in higher education.

\section{INVESTIGATION AND ANALYSIS ON THE CURRENT SITUATION OF THE SYSTEM OF LEADING CADRES CONTACTING CLASSES}

\subsection{Participation of Leading Cadres}

Each group of leading cadres sent out an average of more than 260 questionnaires before contacting the class work. The contents of the questionnaire are divided into objective status survey and subjective evaluation survey. From the objective aspect, we mainly understand the times, forms and time of leading cadres' contact with the class since the implementation of the system of leading cadres' contact with the class. The subjective aspect is mainly to understand the leading cadres' evaluation of the role, value and implementation effect of this system.

According to the questionnaire survey data in recent years, most leading cadres and classes will have many contacts and exchanges, the average annual contact with the class of cadres once a year accounted for $40.7 \%$ of the total, contact twice accounted for $28.8 \%$, contact three times accounted for $10.2 \%$, contact the most times more than 10 times.

Many leading cadres take time out of their own work to contact their classes. The survey shows that most cadres think that the time used to contact classes does not affect the development of their own work. 59.3\% of the cadres think that contacting a class takes up general working time, $28.8 \%$ of the cadres think that it takes up less working time, and $10.2 \%$ of them think that it takes up more time.From the point of view of the way of contact, most cadres and classes take the form of class meetings (36\%), symposiums (28\%), telephone contacts $(19 \%)$ and lectures $(8 \%)$ to implement this work, which shows that class meetings and symposiums are more favored by leading cadres and more concise and effective ways of implementation.

\subsection{Participation and Feedback of Leading Cadres}

In the process of contacting the class, the leading cadres understand the students' ideas and their evaluation and expectation of the school's work through communication with the class. Through contact with the class, many leading cadres said that they also have some harvest. $50.8 \%$ of the cadres thought that this work was of great help and inspiration to themselves, and $11.9 \%$ thought that it was of great help and inspiration.

As an innovative brand of student education in Jinan University, the system of leading cadres contacting classes aims to promote students' learning and development. In recent years, in the process of implementation, we have also received suggestions from all sides: many leading cadres believe that the coverage of the system can be larger, the forms can be more abundant, and it can be expanded into a series of large-scale activities; in addition, we should try our best to arrange activities on non working days. There are also suggestions from leaders that we can arrange senior brothers and sisters who have graduated to participate and share their learning and life experience. 
Most leading cadres believe that through this system, the contact between the class collective and the school administrative department has been strengthened, and some problems existing in the class collective can be reflected in time. $61.2 \%$ of the cadres thought that the system of leading cadres connecting with the class was of great help to the class, and $6.8 \%$ of the cadres thought that the system was of little help to the class. Although contacting the class requires cadres to spend a certain amount of time and energy in various forms of communication with the class, about $80 \%$ of the cadres said that they are still willing to continue to serve as the contact leaders of the next batch of class collectives. $25.4 \%$ of the cadres thought that the communication of class should be carried out in a more voluntary and flexible way. $23.7 \%$ of the cadres thought that this system should further clarify the responsibilities to avoid duplication with the work of the head teacher and counselor. $22.0 \%$ of the cadres thought that the quality of activities should be further improved in the process of connecting with the class, to do practical things for the class, and to really promote the construction of the class and the growth of students.

\subsection{Students' Participation Feedback}

Through the investigation in recent years, it is found that students are more willing to take a more relaxed and lively way to communicate with leading cadres, among which seminars, lectures and exchange meetings are the more recognized ways. Middle and senior students often think that the biggest pressure they face in school comes from employment and postgraduate entrance examination, so they most want to get guidance on employment development from leading cadres. In general, the evaluation of this system is good both inside and outside our school. Leading cadres can help students from the perspective of class teachers and counselors, and hope that the contact system can be improved and carried out continuously.

In the process of participation, students tend to pay more attention to some practical problems. Nearly $86 \%$ of the students hope that the leading cadres can solve the problems of course selection, accommodation and work in some classes. However, the school's implementation of leading cadres' contact with the class aims at leading cadres' starting from ideological and political education, giving students some inspiration and guidance through personal work experience, and inspiring students to learn to learn, think and behave through their own personality charm and life wisdom. Therefore, from the current point of view, the students' understanding of the system of leading cadres contacting the class is not deep enough. Some class students lack the basic understanding of the leading cadres contacted, and fail to give full play to the personal advantages of leading cadres. When we carry out relevant work, we require the class monitor to actively use the platform built by this system to plan theme activities with leading cadres to strengthen the contact between leading cadres and class collective, and provide more accurate help for class students.

\section{THE IMPROVEMENT SCHEME OF THE SYSTEM OF LEADING CADRES CONTACTING CLASSES}

Based on the feedback of leading cadres, counselors, head teachers and students in recent years, the system of leading cadres contacting class needs to be further improved and perfected. On the basis of the existing implementation plan, we need to further strengthen the responsibilities of leading cadres contacting class, clarify the ways of organization, implementation and participation, refine the work requirements, and increase the publicity of achievements The specific improvement plan is as follows.

\subsection{Responsibilities of Leading Cadres}

3.1.1 Strengthen the ideological education of students, help students cultivate and practice the correct outlook on life and values. Help students develop the ability to judge right and wrong, and maintain a healthy and upward state of mind.

3.1.2 Publicize various principles and policies in a timely manner and report the reform, construction and development of the school. Cultivate students' healthy and positive personality, guide and educate students in personal cultivation, civilization and norms.

3.1.3 Focus on the special student groups, grasp the hot spots, difficult points and doubtful points concerned by students in time, and do a good job in solving doubts.

\subsection{Working Style of Leading Cadres}

3.2.1 Attend at least one meeting per academic year. Leaders at all levels can take various forms, such as attending class meetings, student cadres'meetings, teacher-student symposiums, or participating in class collective activities and group day activities, to understand students and help them solve problems and difficulties in their thinking, learning and life. 
3.2.2 Contact or hold at least one lecture per academic year. In-depth contact with the class, discuss various problems of university life with students, and according to the characteristics of the class students, combined with their own professional, experience and other advantages, set up or contact relevant experts or graduated brothers and sisters to set up a lecture for students, to solve students'confusion and expand students' horizons.

3.2.3 Visit the dormitory at least once every school year. Leaders at all levels understand students'learning and living conditions by visiting class dormitories, and timely discover and solve students' problems and practical difficulties.

3.2.4 Keep in touch with the class through Wechat, $Q Q$, e-mail and other means to enhance mutual understanding and carry out ideological and political education.

\subsection{Requirements for the Work of Leading Cadres}

3.3.1 Leaders at all levels should give priority to education and guidance in contact work, and become a bridge between grass-roots class collectives and schools.

3.3.2 Leaders at all levels help students solve practical problems and difficulties by providing advice and suggestions to the class collective in the contact work.

3.3.3 Leaders at all levels should not only fully understand and master the basic situation of students in their study, life and work, but also understand the work of counselors, class teachers and student cadres, and timely feedback to relevant departments to provide basis for the development of teaching management, student management, administrative management and other work in our school.

In the process of implementing the system of leading cadres contacting classes, we should adhere to the fundamental principle of cultivating people by virtue, take teaching and educating people as the core, seize opportunities, innovate with keen determination, promote students'learning and development, create a good class atmosphere and school atmosphere, and cultivate innovative top-notch talents with all-round development of morality, intelligence, physical fitness, beauty and labor.

\section{ACKNOWLEDGEMENT}

This research is strongly supported by the ideological and theoretical education studio of college students in Guangdong Province, and the network ideological and political education counselor studio of Jinan University.

\section{REFERENCE LIST}

Shao Nana, Zhang Hongxia. (2020). The Innovation of College Class Management Mode from the Perspective of Ecology. School Party Construction and Ideological Education (Higher Education Edition), vol. 002.

Bi Qingbo. (2015). Practice and Innovation of College Counselors' Class Management. Science and Technology Innovation Report, vol. 007. 